\title{
LAS RAZONES DE SOR JUANA INÉS DE LA CRUZ ${ }^{1}$
}

\author{
Pablo A. J. BRESCIA \\ University of California, Santa Barbara
}

A Sara Poot Herrera, maestra.

[...] cabeza que es erario de sabiduría no espere otra corona que de espinas.

Respuesta a Sor Filotea de la Cruz.

[...] digo que esto no es replicar, sino referir simplemente mi sentir. Carta Atenagórica.

[las mujeres] ¿no tienen alma racional como los hombres?

Carta al Padre Núñez.

\section{LOS ÚLTIMOS AÑOS DE SOR JUANA}

Cuando Dorothy Schons tituló su señero artículo de 1926 «Some Obscure Points in the Life of Sor Juana Inés de la Cruz» identificó para siempre al formidable adversario con el que se enfrenta la crítica sobre la Fénix de México: esos puntos oscuros, esos segmentos de vida y obra reticentes que ponen en jaque $o$, por lo menos, en lista de espera las investigaciones e interpretaciones sobre la mayor figura literaria del siglo XVII americano. Los últimos años de su vida son

1 Este trabajo desarrolla, desde un enfoque diferente, algunos de los puntos que discutí en «Sor Juana y el Padre Vieira: un baile de disfraces» (1997), «Towards a New Interpretation of the Carta Atenagórica» (1998a) y «El 'crimen' y el castigo: la Carta Atenagórica, de Sor Juana Inés de la Cruz» (1998b). 
especialmente turbios: ¿reclusión voluntaria o involuntaria?; ¿vuelo hacia la virtud o trampas de la fe? Por esta razón, son, además, objeto de controversia.

Pero este apartado inicial no sólo refiere al período 1690-95 sino también a la profusión de estudios críticos en los últimos ocho años (1990-98); son los últimos años sobre sor Juana. Tres factores principales contribuyen a tal interés.

En primer lugar, aparecen las conmemoraciones de su natalicio ( $i 1648$ ? ¿1651?) o de su fallecimiento (1695), junto con el aniversario de la publicación de textos como la Carta Atenagórica (1690, en adelante CA) o la Respuesta a Sor Filotea de la Cruz (1691, en adelante $R S F)^{2}$. Entre algunos de los libros más importantes para el período señalado pueden mencionarse Feminist Perspectives on Sor Juana Inés de la Cruz (1991); «Y diversa de mí misma / entre vuestras plumas ando», homenaje organizado por El Colegio de México en 1991 (1993); la Memoria del Coloquio Internacional Sor Juana Inés de la Cruz y el pensamiento novohispano (1995); el proyecto de la Universidad del Claustro de Sor Juana Sor Juana y su mundo: una mirada actual (1995); la edición de Sor Juana Inés de la Cruz y sus contemporáneos (1998) y el anejo de la revista Tinta, Sor Juana \& Vieira, trescientos años después (1998).

En segundo lugar, debe tenerse en cuenta la continua revisión crítica que sigue suscitando la obra. Entre los múltiples enfoques existentes, cabe señalar el libro de George H. Tavard, Juana Inés de la Cruz and the Theology of Beauty. The First Mexican Theology (1991); el de Alessandra Luiselli, El Sueño manierista de Sor Juana Inés de la Cruz (1993); el de José Pascual Buxó, El enamorado de Sor Juana (1993); el de Margo Glantz, Sor Juana Inés de la Cruz: ¿hagiografía o autobiografia? (1995); y tres volúmenes muy recientes: la colección de artículos de Georgina Sabat de Rivers, En busca de Sor Juana (1998); la lectura que hace Jean-Michel Wissmer en Las sombras de lo fingido: sacrificio y simulacro en Sor Juana Inés de la Cruz (1998) y la monografía de Pamela Kirk, Sor Juana Inés de la Cruz: Religion, Art and Feminism (1998).

La última escena en este panorama tal vez sea la más decisiva. En 1980 los estudios sorjuaninos recibieron una fuerte sacudida con la Carta al Padre Núñez (en adelante $C P N$ ), que se situaría hacia $1682^{3}$. Quince años después, Elías Trabulse da noticias de la Carta de Serafina de Cristo (en adelante CSC), otra carta en torno a sor Juana, firmada el primero de febrero de 1691. El historiador mexicano habla por primera vez de este documento en «La guerra de las finezas.

2 Cito por la edición de Alfonso Méndez Plancarte y Alberto G. Salceda de las Obras completas de Sor Juana Inés de la Cruz (abrevio Méndez Plancarte). En adelante me refiero al cuarto volumen (Comedias, sainetes y prosa) a menos que indique lo contrario.

La carta fue descubierta por el padre Aureliano Tapia Méndez en Monterrey, México. Cfr. Carta de Sor Juana Inés de la Cruz a su confesor. Para la edición y estudio crítico de este documento, cfr. Antonio Alatorre, «La Carta de Sor Juana al P. Núñez». Cito de este trabajo. 
La otra Respuesta a Sor Filotea en un manuscrito inédito de 1691», ponencia leída en el Coloquio Internacional Sor Juana Inés de la Cruz y el pensamiento novohispano (Toluca, México, abril de 1995) ${ }^{4}$. Trabulse, a partir de una secuencia de entregas "parciales», elabora una serie de hipótesis - basadas en recientes hallazgos y datos históricos - que otorgan autoría material de la carta a sor Juana y plantean nuevas relaciones (sospechadas en algunos casos, insospechadas en otros) con los personajes de su entorno. Este proceso culmina con su edición de la CSC en $1996^{5}$. Un año antes, y gracias a la labor de María Agueda Méndez y su equipo de investigación que cataloga los textos marginados por la Inquisición mexicana, aparece un artículo de Ricardo Camarena Castellanos sobre La fineza mayor, sermón leído el 26 de enero de 1691 en el convento de San Jerónimo, en la ciudad de México. En esta oratoria, luego publicada, el clérigo Francisco Xavier Palavicino Villarasa elogia abiertamente a sor Juana ${ }^{6}$. El sermón fue requisado por la Inquisición y su autor reprendido por adular a una «mujer introducida a teóloga y escriturista» (Dorantes 1997, p. 64)7.

Podría arguiirse que esta efervescencia crítica y estos nuevos aportes documentales ya no sugieren sino que obligan a una relectura de la vida y obra de la monja jerónima para reanudar los nexos entre autor, texto, contexto y lector. Mi trabajo se inscribe en esta necesidad y, más específicamente, en las diversas cartas que tienen a sor Juana como remitente o como destinataria. El planteamiento propone una estrategia de correspondencias, es decir, intenta identificar y analizar los cruces entre estos documentos que permitan trazar las coordenadas en las que aspira a moverse y moldearse el «pensamiento sorjuanino». En esta ocasión, reparo en un aspecto poco explorado - la argumentación de la fineza que propone

${ }_{4}$ La ponencia se publica en las memorias del congreso con el título de «La guerra de las finezas».

La autoría material de la carta es una de los aspectos en disputa en este nuevo debate en torno a la monja jerónima. En una nota que hace Ana Cecilia Terrazas en la revista Proceso, Augusto Vallejo dice que la CSC fue dirigida a sor Juana y no escrita por ella; el mismo artículo habla de un peritaje que comprobaría que la carta no es de sor Juana. De reciente aparición es el libro de Antonio Alatorre y Martha Lilia Tenorio Serafina y Sor Juana, quienes hacen una edición crítica de la CSC e intentan refutar varias de las proposiciones de Elías Trabulse, entre ellas, la autoría de esta carta, que atribuyen a Juan Ignacio de Castorena y Ursúa. Las divergencias citadas complican aún más el estado de la cuestión y requieren un análisis pormenorizado. Lo indiscutible es que la CSC hace necesaria la revisión de la vida y de los textos de sor Juana.

6 Esta sección que enumera los hallazgos pertinentes para una reconfiguración de los últimos años de sor Juana se completaría con un re-encuentro: en 1994 Antonio Alatorre edita los Enigmas ofrecidos a la Casa del Placer, texto de la poeta novohispana que Enrique Martínez López, su descubridor, había dado a conocer en 1968.

Cfr. la censura inquisitorial de fray Augustín Dorantes en la edición de Los Ángeles de la CSC. Dorantes se escandaliza ante el «insufrible desorden a citar en el púlpito públicamente a una mujer con aplausos de Maestra, y sobre puntos y discursos escriturales, como consta de la salutación, fol. 3, donde la cita, como dice al margen en su ingeniosa y docta Carta Atenagórica» (p. 64; se modernizó ortografía, puntuación y acentuación). 
sor Juana en la $C A$ - para, desde allí y en relación con las otras cartas, examinar la tensión entre ciertos paradigmas institucionales presentes en el contexto sociocultural de la época y la pugna de sor Juana por construir un espacio físico y textual propio que, a la vez, participe y se diferencie de este contexto.

\section{DOBLE FINAL: EL POST-SCRIPTUM DE LA CARTA ATENAGÓRICA}

El tema visible de la $C A$ es el debate teológico sobre cuál fue la mayor fineza (favor) de Cristo para con los seres humanos. En la primera parte de la carta, sor Juana resume los argumentos que el famoso jesuita portugués Antonio Vieira había urdido en su Sermão do mandato ${ }^{8}$ contra las posiciones de San Agustín, Santo Tomás y San Juan Crisóstomo, defiende las finezas propuestas por éstos y refuta la tesis de Vieira. Aquí se mueve dentro del campo discursivo instaurado por las estructuras jerárquicas (la corte virreinal y los estamentos eclesiásticos, por ejemplo) y los paradigmas ideológicos oficiales de la sociedad novohispana del siglo XVII.

En el terreno de la disquisición teológica, uno de estos paradigmas es la apelación al argumento de autoridad para apoyar el propio razonamiento. El uso que hace sor Juana de este recurso es magistral ya que pone gran cuidado en basar su crítica en las palabras de los Padres de la Iglesia y en las Sagradas Escrituras. Por ejemplo, al detenerse en la posición de San Agustín sobre la fineza de Cristo dice que éste justifica su posición probándola con el texto de Juan 15:13 (maiorem hac dilectionem nemo habet, ut animam suam ponat quis pro amicis suis) y luego por discurso. Sor Juana utiliza la misma estrategia y la desarrolla con otros pasajes:

Pruébase no sólo con el texto: maiorem hac dilectionem, etc., el cual se puede entender de otros amores; sino con otros infinitos. Sea uno en el que Cristo dice que es buen Pastor: Ego sum pastor bonus. Bonus pastor animam suam dat pro ovibus suis, donde Cristo habla de sí mismo y califica su fineza con la muerte (Méndez Plancarte 1951-57, p. 415).

Sor Juana pasa a distinguir dos términos para una fineza ( $a$ quo y ad quem) y a elaborar su argumentación en defensa de San Agustín, apoyándose constantemente en la autoridad del texto bíblico; examina la Resurrección, la Eucaristía, la Encarnación y los pasajes sobre Jacob y Ester, antes de refutar «las razones del autor» (ibid., p. 418). De esta manera, diferencia no sólo su argumentación sino también su método del de Vieira, quien se jacta de no recurrir a la Biblia o la

8 Robert Ricard especula que el sermón, pronunciado en la Capilla Real de Lisboa, se impartió entre 1642 y 1652, pero no en 1650. Cfr. «António Vieira y Sor Juana Inés de la Cruz».

4Juan 10:11. 
Patrística para probar su fineza ${ }^{10}$. La «elación» de este procedimiento debe reprocharse" ya que, según la disertante, «[...] cree el orador que puede aventajar su ingenio a los de los tres Santos Padres y no cree que puede haber quien le iguale» (ibid., p. 435). Sor Juana sabe que es necesario que tanto su argumentación como su estrategia discursiva se conformen de acuerdo con ciertos cánones de escritura y de comportamiento para no «tener ruidos» ${ }^{12}$ con nadie. Por eso, su disquisición sigue los carriles ya señalados. En la conclusión de la primera parte, sor Juana pone lo dicho bajo la censura del destinatario y de la Iglesia Católica - como corresponde a una fiel y obediente monja respetuosa de las instancias superiores- y se despide con un «vale».

Pero hay una posdata: son nueve párrafos que ilustran la tesis de sor Juana sobre la mayor fineza de Cristo. Dice el inicio de esta segunda parte: «Bien habrá V.md. creído, viéndome clausurar este discurso, que me he olvidado de ese otro punto que V.md. me mandó que escribiese: Que cuál es, en mi sentir, la mayor fineza del Amor Divino». Aquí hay un giro: la interpretación propuesta no coincide con ninguna de las reseñadas anteriormente: «Como hablamos de finezas, dije yo que la mayor fineza de Dios, en mi sentir, eran los beneficios negativos; esto es, los beneficios que nos deja de hacer porque sabe lo mal que los hemos de corresponder». Sor Juana razona de la siguiente manera: Dios quiere hacernos finezas ya que va con el «corriente natural» de su infinita bondad, amor y poder. Pero los seres humanos pueden ser ingratos o usar mal los «regalos» divinos, dañándose a sí mismos. Ergo, cuando Dios no nos hace una fineza, nos está haciendo la mayor fineza. Es de notar la estructura paradójica (la palabra refiere etimológicamente a «contrario a la opinión común») del argumento: por lo general se asume que Dios es generoso porque da finezas; aquí se adopta la posición contraria.

10 Si bien es cierto que Vieira usa en ocasiones las palabras de Cristo para apoyar su propuesta sobre la mayor fineza («querer que el amor con que nos amó, fuese deuda de amamos unos a otros») aduce que no se hallarán ejemplos que ilustren este supremo favor en las Sagradas Escrituras: «Por eso me empeñé en decir que dando a todas las finezas de Cristo hoy otra mayor, como hice, a la última que yo señalase, ninguno me había de dar otra que fuese igual. Para las otras finezas, tan celebradas por sus autores y tan encarecidas por sus extremos, tuvimos Magdalenas, Absalones y Davides, que nos diesen ejemplos. Para ésta, ni dentro ni fuera de la Escritura se hallará alguna que se le parezca, cuanto más que la iguale» (cfr. la sección XI de la traducción del sermón del mandato del padre Vieira en Méndez Plancarte 1951-57, pp. 673-694). En torno al problema de la versión «deformada» del sermón de Vieira que leyó sor Juana, cfr. los artículos de Ricard y Manuel Corripio Rivero.

11 Pero la crítica a Vieira es, en su mayor parte, sobre las ideas y no ad hominem. Ricard confirma esta impresión: «Las críticas que sor Juana dirige a Vieira, como lo notó ya el señor Abreu Gómez, atañen únicamente a la dialéctica: lo que discute y combate es su argumentación» (Ricard 1951, p. 75).

12 Recuérdese la tristemente célebre frase de sor Juana en la $R S F$ : «que yo no quiero ruidos con el Santo Oficio» (Méndez Plancarte 1951-57, p. 444). 
Inmediatamente, sor Juana, para proteger su argumentación, apela a la Biblia y halla dos ejemplos de esta abnegada renuncia divina. Del Evangelio de San Mateo recoge la crítica que le hacen los habitantes de Nazareth a Cristo. A causa de esta ingratitud, el Hijo de Dios decide no hacerles finezas para, según sor Juana, «no darles la ocasión de cometer mayor pecado» ${ }^{13}$. Del Génesis toma el diluvio universal para demostrar las consecuencias de una fineza mal utilizada. Dios se ha regocijado en la creación del mundo pero, ofendido por la maldad demostrada por sus criaturas, decide destruir a los seres humanos y sentencia: "me arrepiento de haberlos hecho». Aparece luego en esta prueba un «desvío» que trata el tema de la envidia; a esto volveré más adelante. Hacia el final, sor Juana arguye que esta definición «negativa» de fineza debe trascender el discurso especulativo y transformarse en servicios prácticos; de este modo, las finezas adquirirán una cualidad positiva. Sor Juana mantiene entonces la coherencia entre su definición general de fineza (actos de amor, con el énfasis en «actos») y la argumentación con la que propone su propia fineza, ya que ambas postulan un pasaje de la reflexión teológica a la ejecución práctica (ibid., pp. 435-439) ${ }^{14}$.

Dentro de la intrincada argumentación de la $C A$, sor Juana intenta crear un espacio que nazca de la intersección entre las diversas reglas (conventuales, inquisitoriales, de amistad y recelo) que regulan el discurso novohispano y la libertad de razonamiento a la que aspira su propia intelectualidad. En esta carta, que ha sido entendida bien como disertación teológica, bien como manifiesto político, la fineza propuesta por sor Juana incluye una dimensión personal cuya textualización apunta a la formación de un pensamiento. Este pensamiento, presente en otros textos pero muy especialmente en las cartas que rodean a sor Juana, se basa en dos pilares centrales: la envidia y el libre albedrío, elementos que examino a continuación.

13 La Biblia dice que Cristo «no hizo allí muchas maravillas, a causa de la incredulidad de ellos» (Mateo 13:58).

${ }^{14}$ El tema de las finezas es recurrente en la obra de sor Juana. Enrique Martínez López cita algunos de los lugares donde aparece: la Loa para El mártir del Sacramento, San Hermenegildo, algunas escenas de Los empeños de una casa y Amor es más laberinto, el Sarao de las cuatro naciones y varias otras loas (Martínez López 1968, pp. 63-64). También Octavio Paz (1989, p. 514) y posteriormente Margo Glantz (1990) hablan de las finezas en El divino Narciso. Para un estudio del papel de la fineza en Los empeños de una casa, cfr. «Las finezas de Sor Juana» (Franco 1993, pp. 247-256); para la relación entre este tópico y «Las letras de San Bernardo» de sor Juana, cfr. «Una carta finamente calculada: la de Serafina de Cristo» (Poot Herrera 1998, pp. 127-141). 


\section{EN PERSEGUIRME, MUNDO, ¿QUÉ INTERESAS ${ }^{15}$}

El tema de la envidia es medular en la $C P N$. Allí, sor Juana se queja de su situación y enarbola una defensa que pone en escena -con impecable humorlas contradicciones que resultan de la combinatoria de acusaciones que formulan sus detractores:

¿De qué envidia no soy blanco? ¿De qué mala intención no soy objeto? ¿Qué acción hago sin temor? ¿Qué palabra digo sin recelo? Las mujeres sienten que las exceda. Los hombres, que parezca que los igualo. Unos no quisieran que supiera tanto. Otros dicen que había de saber más, para tanto aplauso. Las viejas no quisieran que otras supieran más. Las mozas, que otras parezcan bien. $Y$ unos y otros, que viese conforme a las reglas de su dictamen (Alatorre 1987, pp. 620-621; se moderniza ortografía).

Debe recordarse, sin embargo, que sor Juana se dirige a su por entonces confesor. Como observa Mabel Moraña: «en este juego de apropiaciones y máscaras barrocas, Núñez de Miranda es siempre el otro [...] Esta posicionalidad variable del otro requiere de la monja una similar capacidad de acomodación retórica y pragmática» (Moraña 1998, p. 323). El padre Núñez es uno de los personajes centrales, aunque no único, para examinar la envidia como tema y problema en la obra de sor Juana.

Lo que me interesa subrayar aquí es el uso insistente que hace sor Juana de este tópico que «no será materia para una carta, sino para muchos volúmenes muy copiosos» (Alatorre 1987, p. 621). A pesar de que no pueda elaborar un tratado sobre el asunto, sor Juana le da otro uso: argumenta con él. Es de notar que, en la $C A$, la prueba que utiliza para su fineza recorre un curioso camino: de una estructura de «prúebase por discurso-pruébase por texto»--es decir, enunciado que plantea una hipótesis-ejemplos que confirman la validez de la proposicióna una diatriba (¿digresión?) contra la envidia ${ }^{16}$. En el Comulgador Penitente (la primera edición de este volumen es de 1664; se vuelve a editar en 1690 en la misma imprenta que imprime la $C A$ ) Núñez combina varios de sus intereses: la doctrina de la frecuente comunión, la regla 18 de la Congregación de la Purísima y, por supuesto, la admonición a las monjas. Allí exclama:

Pues tú, que eres hija de Dios, ¿cómo no te desprecias, antes te precias de tan viles ejercicios; olvidada de ti misma de tu sobrenatural ser, de tus altas y (en realidad de verdad) divinas obligaciones. Dime, ¿esos pensamientos en que

15 Primer verso del conocido soneto - 146 según la clasificación de Méndez Plancarte- de sor Juana (Méndez Plancarte 1951-57, vol. 1, pp. 277-278).

16 Rosa Perelmuter ha señalado que tanto la $C A$ como la $R S F$ siguen las divisiones retóricas del discurso forense (exordio-narración-prueba-peroración), aunque en la $R S F$, dado su tono familiar, la narración y no la prueba es la sección más extensa. 
te devanas son dignos de una hija de Dios? Esas ocupaciones, esos divertimientos, esos designios, ¿son dignos de una hija de Dios?

Esta exhortación parece hecha para sor Juana (Trabulse 1995a, pp. 56-57). En la $C A$, podría ser sor Juana la que exhorta ahora a Núñez cuando dice, como parte de esa diatriba contra la envidia:

Envidiamos en nuestros prójimos los bienes de fortuna, los dotes naturales. ¡Oh, qué errado va el objeto de la envidia, pues sólo debía serlo de la lástima el gran cargo que tiene, de que ha de dar cuenta estrecha! Y ya que queremos envidiar, no envidiemos las mercedes que Dios le hizo, sino lo bien que corresponde a ellas, que esto es lo que se debe envidiar, que es lo que da mérito; no el haberlas recibido, que eso es cargo (Méndez Plancarte 1951-57, pp. 438-439; énfasis mío).

Son las maneras de hacer uso de las «mercedes» que Dios nos dio -y no las mercedes mismas, que son naturales y representan un agobio- las que deben ser objeto de envidia. Hay un error en la argumentación de estos «envidiosos». Si quieren envidiar, envidien bien, parece decir la monja jerónima.

Este uso de la envidia como herramienta argumentativa privilegiada reaparece en la $R S F$. Además de la admirable narrativa sobre la inclinación a las letras, hay en este texto tres pasajes definitorios. Dos de ellos son ya clásicos para los estudiosos de sor Juana: el catálogo de mujeres sabias (ls. 845-907) y la disquisición sobre el dictum de San Pablo Mulieres in Eclesils taceant (1s. 908-1259). El otro requiere atención especial en este trabajo: las reflexiones sobre la envidia (ls. $527-$ 714). Allí, sor Juana toma el motivo de aquel «que se señala —o le señala Dios, que es quien sólo lo puede hacer- $-[y]$ es recibido como enemigo común» y se hace eco de la máxima de Maquiavelo — «aborrecer al que se señala porque desluce a los otros»-17 para equiparar sus pesadumbres con las sufridas por Cristo ante los fariseos. Sor Juana enfatiza lo inexplicable - ¿ lo irracional? - del sufrimiento del Hijo de Dios, condenado por hacer milagros: «¿Cómo es posible que [...] no les arrebatara las almas, que no fuesen enamorados y elevados tras él?». La irritación de sor Juana es tal que no puede dejar de señalar que «así es, que cuando se apasionan los hombres doctos prorrumpen en semejantes inconsecuencias», un tiro por elevación no demasiado elevado hacia sus críticos. Sor Juana luego dedica la parte final de su argumento a comentar críticamente la

17 Sor Juana habla de la «ley políticamente bárbara de Atenas» que, como bien explican Méndez Plancarte y Salceda, es el ostracismo. Señalan además que, en su Romance al Caballero del Perú que le enviara unos barros, sor Juana vuelve a mencionar esta ley; yo agregaría que aprovecha para volver al tema de la envidia: «El que a todos aventaja,/fuerza es que a todos incite/ a envidia, pues el lucir/a todos juntos impide//Al paso que la alabanza/a uno para blanco elige/ a ese mismo paso trata/ la envidia de perseguirle» (Méndez Plancarte 1951-57, p. 653 y vol. 1, p. 139, ls. 125-132). 
corona de espinas que recibe Cristo de $\operatorname{los}$ soldados ${ }^{18}$ y el milagro de la resurrección de Lázaro; es decir, hace una exégesis de nuevos pasajes bíblicos para apoyar su argumentación. Concluye que «menos intolerable es para la soberbia oír las reprensiones que para la envidia ver los milagros» (Méndez Plancarte 1951-57, pp. 453-457).

El tópico de la envidia en la $C A$ y en la $R S F$ le sirve a sor Juana para defender su «infeliz habilidad de hacer versos» (ibid., p. 452). La idea se relaciona con su perspectiva acerca del talento natural; en la $R S F$ habla de «este natural impulso que Dios puso en mí» (ibid., p. 444). Lógicamente, no podría criticarse algo dado por vía natural (y no adquirida) porque no se ha participado en su elección; es más, según la monja jerónima, es «cargo». Renunciar (como quería Núñez y tal vez otros personajes de su entorno) a este «don» sería contra natura $\mathrm{y}$, dado que Dios dispone los bienes naturales, contra la voluntad divina.

\section{NACÍ CON [ESTE GENIO] Y CON ÉL HE DE MORIR ${ }^{19}$}

Esta determinación de vivir y morir respetando sus propias convicciones alude al tema del libre albedrío, el otro elemento clave en la formación del pensamiento de sor Juana. Las estrategias argumentativas y la fineza propuesta en la $C A$ hallan su fundamento en esta noción. La autora no se basa en las Sagradas Escrituras al enunciar su «sentir» aunque, como se dijo anteriormente, sí apoya su demostración con algunos ejemplos bíblicos. Su tesis habrá escandalizado a muchos; la primera crítica conocida es la del obispo de Puebla Manuel Fernández de Santa Cruz en la Carta de Sor Filotea de la Cruz (en adelante CSF), texto que servirá de «prólogo» a la $C A$ :

Por más que la discreción de V. md. les llame finezas [a los beneficios negativos], yo los tengo por castigos: porque sólo es beneficio el que Dios hace al corazón humano previniéndole con su gracia para que le corresponda agradecido, disponiéndose con un beneficio reconocido, para que no represada, la liberalidad divina se los haga mayores (Méndez Plancarte 1951-57, p. 696) ${ }^{20}$.

La apuesta de sor Juana por la libertad de acción era, si no radical, sí arriesgada, aun dentro de la polémica que suscitó el tema en su época ${ }^{21}$. Para su

18 Para un análisis de esta parte de la $R S F$, «comparación amplificatoria cuyo fin principal es la moción de afectos», cfr. el análisis retórico que hace de esta carta Kolđobika Josu Bijuesca (Bijuesca 1998, esp. pp. 96-98, y sobre el tema de la identificación entre sor Juana y Cristo n. 10).

19 Línea 197 de la CPN (Alatorre 1987, p. 623).

20 Para un examen de las tácticas de Fernández de Santa Cruz en esta carta, cfr. Enrique Martínez López, «Sor Juana, Vieira y Justo Lipsio en la Carta de Sor Filotea de la Cruz».

21 Según Octavio Paz, la discusión planteada en la $C A$ y la fineza propuesta por sor Juana «son un eco de las grandes polémicas de su tiempo sobre la gracia y el libre albedrío» (1989, p. 518). 
posición de mujer (monja) e intelectual en el siglo XVII novohispano, lugar que requería un precario equilibrio entre obediencia debida y vocación librepensadora, proponer que el regalo más grande que nos hace Dios es sacrificar su propia libertad para dejarnos libres y poder manejar así nuestro propio destino era exponerse a reproches como los de Fernández de Santa Cruz, e incluso más serios.

En la CSC se dice que ha salido «no sé qué soldado castellano a la demanda del valentísimo Portugués» (Carta de Serafina de Cristo, p. 37) ${ }^{22}$. Si se lee «demanda» como defensa de Vieira - según el DRAE, «salir a la demanda» es, en términos forenses, mostrarse parte en un pleito, oponiéndose al que es contrario en él y, en su acepción figurativa, hacer oposición a otro o defender alguna cosa- es claro que había oposición a la postura de sor Juana y a su «intromisión» en asuntos teológicos. Un lector contemporáneo como Robert Ricard, por ejemplo, se quejaba de las complicaciones silogísticas que usa sor Juana para rebatir a Vieira y, en cuanto a la fineza que postula la poeta novohispana, comentaba:

¿Quién no se juzgaría defraudado? Esta carta, en la que una emoción sincera y un sentimiento profundo surgen a menudo debajo de la pedantería escolástica y la agudeza, a veces fuera de lugar, de una preciosidad sutil, acaba por un juego de espíritu. En una obra anterior, la monja mexicana había hecho de la Encarnación la mayor fineza de Cristo; aquí, y aun teniendo en cuenta que no habla de Cristo encarnado, sino de Dios, puede decirse que la mujer de letras ha vencido a la religiosa (Ricard 1951, p. 70).

$\mathrm{El}$ argumento que presenta sor Juana no lo convence; a Ricard no se le escapa la posible analogía entre su reflexión y la carta del obispo de Puebla, escrita dos siglos y medio antes; incluso indica que sor Filotea «no se equivocaba del todo» (id.). En un artículo muy reciente Emil Volek, desde una mirada favorable hacia sor Juana y crítica hacia Fernández de Santa Cruz, habla de la lógica «algo torcida» del suplemento de la $C A$ y de su «dialéctica alucinante» (Volek 1998, p. 339). Habría que examinar si esto realmente es así, si se considera el hecho que sor Juana labora para formar su pensamiento de acuerdo con los dos ejes que se han venido discutiendo en este trabajo $y$, por ende, construye su propia lógica. El mismo Volek entiende que, aunque sor Juana cuenta con instrumentos inadecuados (afirmación discutible), «en el escrito de la autora no se trata sólo de teología: su fin y su tema final es la libertad humana» (ibid., p. 348).

22 Según la censura de Dorantes, en el final de la dedicatoria de su sermón Palavicino habla de una cordera (Agnes, es decir Inés) contra quien vibró la cruel lanza de un «ciego soldado». Esto refiere a un papel imputado a Palavicino (imputación que el clérigo niega) que se divulgó «contra otro papel de dicha religiosa», es decir, contra la $C A$ (Dorantes 1997, pp. 63-64). El «soldado» que mencionan la CSC, Palavicino y Dorantes es seguramente el mismo. El enigma de su identidad desvela a los sorjuanistas. 
Como dice la monja jerónima en la $C A$, «es menester acordarse que Dios dio al hombre libre albedrío con que puede querer y no querer obrar bien o mal, sin que para esto pueda padecer violencia, porque es homenaje que Dios le hizo y carta de libertad auténtica que le otorgó» (Méndez Plancarte 1951-57, p. 431). Ese «homenaje» es la fineza mayor para sor Juana. La pregunta es: ¿fue imprudente esgrimir esta carta en esta instancia, de esta manera? Lo que puede afirmarse sin temor al equívoco es que el concepto de libre albedrío, esencial para entender la lucha por crear un discurso propio, es congruente con la apología de la vocación intelectual en la $R S F$ y con la defensa armada en la $C P N$.

Con este tópico sor Juana organiza un contraataque contra aquellos que impugnan sus actividades. En la $C P N$ invoca el asunto para interpelar a Núñez: «¿Cuál era el dominio directo que tenía V.R. para disponer de mi persona y del albedrío (sacando el que mi amor le daba y le dará siempre) que Dios me dio?»; más adelante pregunta, ya en tono de franca sorna: «¿Restringióse y limitóse la misericordia de Dios a un hombre, aunque sea tan discreto, tan docto y tan santo como V.R.?» (Alatorre 1987, pp. 623, 626). Nótese cómo se contrapone la figura divina - símbolo de libertad - a la figura de Núñez, que evoca palabras como «dominio», «restricción» y «límite». Sor Juana reclama su derecho a elegir y a despedir, si fuera necesario, a su confesor espiritual. Sin embargo, en la Plática doctrinal (1679) Núñez señala que el voto de obediencia significa la renuncia de las monjas al libre albedrío. María Dolores Bravo afirma que el Testamento místico de Núñez (publicado póstumamente) «demanda de la religiosa una absoluta autoenajenación, física, intelectual y anímica» (Bravo 1993, p. 41); estos dos ejemplos provocarían una evidente fricción con la «disposición natural» de sor Juana $^{23}$. Con la $C P N$ la monja jerónima se despide de su confesor, pero los últimos hallazgos apuntan hacia una continuidad en el hostigamiento o, al menos, un sostenido recelo por parte de Núñez o de personajes asociados con é $1^{24}$ ¿Cómo proceder frente a esta encrucijada?

En la $C A$, para afirmar el derecho a réplica sor Juana planeó una estrategia: contrastó su «humildad» frente a la supuesta arrogancia de Vieira y, quizás, de sus críticos: «A vista del elevado ingenio del autor aun los muy gigantes parecen enanos. ¿Pues qué hará una pobre mujer?» (Méndez Plancarte 1951-57, p. 434). La extensión del término «autor» podría pasar de la «máscara» de Vieira (sor Juana no lo nombra en la $C A$; sí aparece en la $C S F$, en la $C S C$ y en la $R S F$ ) a Núñez ${ }^{25}$ y a otros oscuros personajes. Sor Juana, «pobre mujer», no sólo inicia

23 Ezequiel Chávez se ocupa de este «choque de almas».

24 Tanto fray Augustín Dorantes como Alonso Alberto de Velasco —el prelado que denunció el sermón de Palavicino a la Inquisición - eran, según Juan Antonio de Oviedo (biógrafo del padre Núñez), alumnos dilectos del ex-confesor de sor Juana. Agradezco la suministración de este dato a Sara Poot Herrera.

25 Ésta es la tesis que maneja Elías Trabulse. Cfr. Carta Atenagórica de Sor Juana. 
con esta estrategia la defensa de su vocación de escritora y pensadora - luego cristalizada en su brillante y valiente respuesta autobiográfica- sino que también solidifica los ejes de su pensamiento. En la $R S F$ la mayoría de las referencias a la libertad de elección se enlazan explícitamente con la $C A$, ese «crimen» que ha cometido:

¿Fue aquella más que referir sencillamente mi sentir con todas las venias que debo a nuestra Santa Madre Iglesia? Pues si ella, con su santísima autoridad, no me lo prohíbe, ¿por qué me lo han de prohibir otros? ¿Llevar una opinión contraria de Vieyra fue en mí atrevimiento, y no lo fue en su Paternidad Ilevarla contra los tres Santos Padres de la Iglesia? Mi entendimiento tal cual ¿no es tan libre como el suyo, pues viene de un solar? ¿Es alguno de los principios de la Santa Fe, revelados, su opinión, para que la hayamos de creer a ojos cerrados? (ibid., p. 468).

¡Ay, la incorregible sor Juana y sus preguntas! Aquí el cuestionamiento parece personal pero no lo es: sor Juana opone al discurso oficial que calla la palabra del «débil», en términos - no absolutos, por cierto- de Josefina Ludmer, el derecho (masculino y femenino) al disentimiento porque «como yo fui libre para disentir de Vieyra, lo será cualquiera para disentir de mi dictamen» (ibid., 469). Este derecho, arguye la poeta novohispana, está protegido por la Santa Madre Iglesia - máxima autoridad- en tanto uno observe los procedimientos del caso («venias»); a él recurre al despedirse de su confesor: «Conque podré gobernarme con las reglas generales de la Santa Madre Iglesia mientras el Señor no me da luz de que haga otra cosa, y elegir libremente padre espiritual» (Alatorre 1987, p. 626). Destaca el énfasis que sor Juana pone en el entendimiento para cimentar su posición, rasgo que se repite en otros momentos y que sería clave para la conformación de su pensamiento.

\section{UN EXTRAÑO GÉNERO DE MARTIRIO ${ }^{26}$}

La reflexión sobre la envidia y el libre albedrío en las cartas que rodean a sor Juana (enfocada en estas páginas no tanto en su variante temática sino en su utilización como estrategia argumentativa) ha tenido como objetivo analizar la tensión que se produce entre discurso institucional y espacio subjetivo, contexto y texto, paradigmas ideológicos oficiales y paradigmas alternativos. En estas conclusiones, lo que planteo son una serie de hipótesis que esperan su demostración; la idea es construir perspectivas que aspiren a identificar algunos de los puntos centrales del «pensamiento sorjuanino».

26 En la CPN sor Juana habla del «tan extraño género de martirio» que sufre (Alatorre 1987, p. 620) y en la $R S F$ exclama: « Rara especie de martirio donde yo era el mártir y me era el verdugo!» (Méndez Plancarte 1951-57, p. 452). 
En el espacio personal que construye sor Juana para su discurso, la envidia, como se ha visto, tiene una función importante. ¿Cuál sería la correspondencia que subyace en el plano público? Podría postularse un paradigma de la competencia. Según el padre Calleja, sor Juana, a los ocho años, compite por un premio (un libro, por supuesto) y compone una loa; a los diecisiete años ocurre el famoso examen ante los cuarenta sabios, aprobado con mayúsculo éxito (Calleja 1980, pp. 141, 143). Luego sigue la competencia literaria imaginaria con Quevedo, Lope, Calderón y el magno Primero Sueño, de tintes gongorinos. En la Nueva España, se «enfrenta» amistosamente con Carlos de Sigüenza y Góngora en la composición de arcos triunfales ${ }^{27}$ y no tan amistosamente con el padre Núñez, también autor de arcos triunfales, villancicos y profuso tratadista religioso ${ }^{28}$.

¿Cómo responde sor Juana a este paradigma de la competencia? Lo concibe como diálogo, como estímulo intelectual, como prueba de inteligencia y entonces su obra se transforma en el inextinguible sol del cielo literario novohispano ${ }^{29}$. Éste sería el efecto positivo. Es aclamada; el motivo del "aplauso no solicitado» aparece en la $C P N$ («los aplausos y las celebraciones vulgares ¿los solicité?» Alatorre 1987, p. 621) y en la $R S F$ («iquién no creerá, viendo tan generales aplausos, que he navegado viento en popa y mar en leche?» Méndez Plancarte 1951-57, p. 452). Y tanto el sermón predicado por Palavicino como la CSC demuestran que la competencia sobre ciertos asuntos (las finezas de Cristo, por ejemplo) podía ser peligrosa. Ahora bien, ¿cómo responden los otros ante el ineludible protagonismo de la monja jerónima? Con la envidia. Alatorre y Trabulse han tratado el tema de los «celos profesionales» que podía haber suscitado la fama de sor Juana en el padre Núñez, por ejemplo (Alatorre 1987 y Trabulse 1995a). No sería el único caso, seguramente. Éste sería el efecto negativo. Pero lo que aparenta ser queja en sor Juana se convierte en estrategia de pensamiento y argumentación: contra la envidia, defiende los dotes naturales y sólo la justifica cuando éstos se utilizan erróneamente, es decir, cuando las acciones «no corresponden» a las mercedes que otorga Dios. Y aquí se produce un enlace significativo: en la $R S F$ sor Juana habla de la «fuerza de su inclinación» y de los problemas que ha tenido por ello:

${ }_{27}$ Cfr. por ejemplo las composiciones que hacen sor Juana (Neptuno Alegórico) y Sigüenza y Góngora (Teatro de virtudes políticas) para la celebración de la llegada del nuevo virrey, el marqués de la Laguna, a la capital mexicana en 1680. Para un análisis comparativo, cfr. Fernando Checa, «Arquitectura efímera e imagen del poder» (Checa 1995, pp. 283-305).

28 Para un examen de la relación de competencia entre sor Juana y los hombres, cfr. Antonio Alatorre, «Sor Juana y los hombres».

29 En «Las cartas de Sor Juana: públicas y privadas», Sara Poot Herrera se refiere a la conversación que sor Juana tenía con el mundo, con la publicidad del siglo: «Sor Juana habla con los demás, con los otros, con los que están fuera del convento y, que a su vez, tienen contacto con personalidades que de una u otra manera están cerca de ella. Hay redes importantes de relaciones de amistad, políticas, religiosas» (Poot Herrera 1998b, p. 316). 
Entre las flores de esas mismas aclamaciones se han despertado tales áspides de emulaciones y persecuciones, cuántas no podré contar, y los que más nocivos y sensibles para mí han sido, no son aquellos que con declarado odio y malevolencia me han perseguido, sino los que amándome y deseando mi bien ( $y$ por ventura, mereciendo mucho con Dios por la buena intención) me han mortificado y atormentado más que los otros (Méndez Plancarte 1951-57, p. 452).

En este pasaje se aúnan el motivo del «aplauso no solicitado», el tema de la envidia, resultado del paradigma de la competencia, y tal vez haya que pensar en algo más: ¿no estará poniendo a funcionar sor Juana su teoría sobre los beneficios negativos, aplicada a su caso? Se diría que es una exhortación a sus más «amorosos» detractores (vaya paradoja): «no me hagan más favores, que la mayor fineza es dejarme libre», parece decir sor Juana.

En la competencia sor Juana funciona adecuadamente. El efecto nocivo de este paradigma (el discurso «envidioso» de los otros) perturba su espacio privado y por esto se apropia del tópico y lo convierte en estrategia de argumentación. Con el libre albedrío es al revés: la respuesta privada de sor Juana ante el paradigma público de la obediencia - uno de los cuatro votos, junto con el de castidad, pobreza y clausura, que hacían las religiosas al enclaustrarse - perturba el espacio oficial de las reglas religiosas y, en consecuencia, a sus intransigentes defensores. El tema es prevalente en las cartas de sor Juana. En la $C P N$, sor Juana aduce que haberse rehusado a componer el Neptuno Alegórico «era inobediencia» (Alatorre 1987, p. 619); en la $C A$ repite constantemente que la escribe porque se lo han pedido y debe responder (Méndez Plancarte 1951-57, p. 412 y passim); en la $R S F$ protesta que sólo escribe por obedecer y habla de la «reverencia» que le debe a Fernández de Santa Cruz (ibid., pp. 464, 474-475).

Asunción Lavrin, entre otras, ha incursionado e iluminado el terreno de la obediencia debida de las monjas hacia sus superiores. En «Vida conventual: rasgos históricos» dice que la $R S F$ es una mezcla de desafío y atrición. Por eso concluye: «el cuerpo de la Respuesta es una mezcla de expresión de libre albedrío y de reiteración de obediencia» (Lavrin 1995, pp. 56-63). Recuérdese la admonición de Fernández de Santa Cruz en la CSF: «Letras que engendran elación, no las quiere Dios en la mujer; pero no las reprueba el Apóstol cuando no sacan a la mujer del estado de obediente» (Méndez Plancarte 1951-57, p. 695). Sin embargo, se ha visto cómo sor Juana defiende su derecho a pensar libremente y cómo se vale de esa opción en sus argumentaciones; cuando es necesario, sólo declara obediencia a la Santa Iglesia. Habría que decir que este énfasis en la libertad de pensamiento es lo que permite a las lecturas feministas hablar de un «reto al orden falocéntrico literario» en la obra de sor Juana (por ejemplo, Bergmann 1983, p. 182). Lo que destaca del análisis de Lavrin y que sirve a nuestro enfoque es ese vaivén áspero entre la presunta libertad del espacio literario y la camisa de fuerza instaurada en la vida de la mujer en el siglo XVII; esto también se convierte en 
estrategia argumentativa para sor Juana. Uno no puede dejar de preguntarse sobre las causas del ocaso del libre albedrío (léase la escritura) ${ }^{30}$ en la poeta novohispana y plantearse si no fue un «exceso de obediencia» (la redacción de la $C A)^{31}$ lo que provoca el colapso final.

Frente a la tensión entre paradigmas públicos (competencia/ obediencia) y respuestas públicas (brillo intelectual/cumplimiento formal) y privadas (argumentación a partir de la envidia; argumentación a partir del libre albedrío), ¿existe una tercera vía, un atisbo de resolución en la obra de sor Juana? En otro trabajo, me he ocupado de señalar las posibles direcciones de relectura de la $C A^{32}$. Una de ellas propone concentrarse en la fineza que presenta sor Juana como condensadora de esos conflictos. ¿Es en el post-scriptum de la carta donde sor Juana intenta, por un lado, mantener una arquitectura argumentativa que atiende tanto a los procedimientos retóricos de la época como a los paradigmas señalados (aun en un documento que, en principio, era de carácter privado) y, por el otro, rebatir ya no a Vieira sino a sus detractores a partir de ejes de pensamiento propios?

En este delicado juego de proporciones, sor Juana no pierde nunca la razón. Una hipótesis posible es entonces construir un paradigma (marginal) para caracterizar el pensamiento de sor Juana: la racionalidad. En la $R S F$ dice confesarse «con la verdad y claridad que en mí es siempre natural y costumbre»; intenta justificar su inclinación a las letras porque se lo indicó «la primera luz de la razón»; al ocuparse de los sufrimientos de Cristo dice que la eminencia que más padece la envidia «es la del entendimiento» (Méndez Plancarte 1951-57, pp. 443, $444,455)$. La razón es natural en sor Juana; hasta el mismo Fernández de Santa Cruz lo reconoce (y refuerza el argumento sobre los «dotes naturales» que alberga la monja jerónima): «Éste [la claridad, compañera de la sabiduría] es uno de los muchos beneficios que debe V. md. a Dios; porque la claridad no se adquiere con el trabajo e industria: es don que se infunde con el alma» (ibid., p. 694). Esta claridad fundamentada en la razón y conjuntada con el ánimo inquisitivo es quizá lo que irrita a algunos de sus lectores.

30 Algunos de los últimos hallazgos desmienten la idea de una sor Juana «retirada» de las letras en sus últimos años. Los Enigmas, por ejemplo, llevan como fecha de publicación el año de 1695 y se cree que fueron compuestos sólo algunos años antes. En el Congreso Internacional Sor Juana y su mundo: una mirada actual celebrado en México D. F. en noviembre de 1995. Teresa Castelló Iturbide dio a conocer una copia del inventario que se levantó en la celda de la monja después de su muerte y que registra cientos de volúmenes de obras selectas y varios legajos de escritos. Esto serviría de testimonio que la vocación de sor Juana estaba viva, aunque tal vez confinada más y más a la marginalidad frente a la imagen que proponían los otros.

31 Ante la advertencia de sor Filotea de que ocupe su tiempo en asuntos religiosos («ya será razón que se perfeccionen los empleos y se mejoren los libros»), sor Juana, en la $R S F$ dice que envía al prelado los Ejercicios de la Encarnación y los Ofrecimientos de los Dolores. En apariencia, cumple una vez más con las formas de la obediencia (Méndez Plancarte 1951-57, pp. 695, 473-474). $93-96$

32 Cfr. «El 'crimen' y el castigo: la Carta Atenagórica, de Sor Juana Inés de la Cruz», esp. pp. 
En la $C A$, el contexto es diferente. Sor Juana se refiere primero al «entendimiento humano, potencia libre y que asiente o disiente necesario a lo que juzga ser o no ser verdad». La libertad de pensamiento vuelve a aparecer, esta vez como calificadora de la razón ${ }^{33}$. Más adelante, y teniendo en cuenta el asunto que la mueve a escribir, sor Juana no deja de recordar que a ella le interesa la argumentación: «Allá verá V. md. en el sermón lo elegante de esta prueba; que a mí me importa, primero, averiguar la forma de este silogismo, y ver cómo arguye el Santo [Tomás] y cómo replica el autor». La razón se liga aquí a la argumentación silogística: «pruébolo por razón», dice sor Juana (ibid., pp. 413, 420, 425). Y es justamente la argumentación de la $C A$ «la viveza de los conceptos, la discreción de sus pruebas»- lo que admira sor Filotea (ibid., p. 694). Como ejemplo de esta «viveza» no puede dejar de citarse el argumento que presenta sor Juana para refutar la proposición de Vieira sobre el llanto de Magdalena por Cristo, ausente al pie de la cruz y presente ante el sepulcro. Vieira infiere que hay mayor dolor en la ausencia que en el momento de la muerte. Sor Juana contesta que un dolor muy grande inhibe nuestras acciones y movimientos; cuando se modera, se exhala el llanto, «de donde se prueba, por razón natural, que es menor el dolor cuando da lugar al llanto [...] luego no son indicio de muy grave dolor las lágrimas, pues es un signo tan común, que indiferentemente sirven al pesar y al gusto» (ibid., pp. 418-419).

Las pruebas textuales que permiten hablar de la racionalidad como rasgo central en el pensamiento de sor Juana están ya condensadas en la $C P N$. Allí, dos veces aparece el conflicto entre fuerza y razón: «Ojalá y la santidad fuera cosa que se pudiera mandar, que con eso la tuviera yo segura. Pero yo juzgo que se persuade, no se manda». Sor Juana se reserva la capacidad de juzgar (razonar) la viabilidad de una proposición. Ante el afán que muestra Núñez por indicarle el camino de la salvación, sor Juana hace una distinción clave: «Si es mera caridad, parezca mera caridad y proceda como tal, suavemente, que el exasperarme no es buen modo de reducirme, ni yo tengo tan servil natural que haga por amenazas lo que no me persuade la razón» (Alatorre 1987, p. 624; énfasis mío). Más allá de la lección doctrinal que le da sor Juana a su confesor (la caridad es suave y usted no lo es), lo que se deduce de este pasaje es que el único modo de persuasión válido para sor Juana es la argumentación razonada; su naturaleza rechaza otros métodos que no se conducen con su «servil natural» ${ }^{34}$. Y aquí hay otro cruce posible; la frase se enlazaría con lo que dice Calleja en su biografía: «la caridad era su virtud

33. Alatorre dice que, cuando sor Juana discute en la CPN la composición del Neptuno Alegórico y considera las posibles respuestas que hubiera podido dar, nunca piensa en la que Núñez hubiera pensado para ella: «tendré que consultarlo con mi confesor». Es claro para Alatorre que sor Juana «no razona como monja, sino como mujer seglar, como mujer libre» (Alatorre 1987, p. 668).

34 Alatorre refiere a la pugna entre razón y fuerza que aparece en la acción de la Loa del Divino Narciso (Alatorre 1987, p. 663, n. 114). 
reina: si no es para guisarlas la comida, o disponerlas los remedios a las que enfermaban, no se apartaba de su cabecera» (Calleja 1980, p. 145) y también con la caridad, virtud de los serafines de Dios, como posible respuesta a la envidia, relación que examina Sara Poot Herrera en un trabajo reciente ${ }^{36}$.

Como vimos en nuestro recorrido por las cartas que rodean a sor Juana ${ }^{37}$, desde una lectura moderna puede argumentarse que el poder equitativo y universal de la razón para persuadir - no el de la emoción ni el del autoritarismo- fue algo en lo que la monja jerónima creyó con fervor, no así sus contemporáneos. Por esto, este paradigma racional, para seguir con las paradojas, no era modelo o, por lo menos, no era un modelo oficial y, por tanto, aplicable. La racionalidad, en el caso de sor Juana, debía ser neutralizada por la obediencia y la envidia. En los intersticios de su obra, sor Juana se permitió diferir. Por eso la pregunta de la (sin dudas ya) pensadora novohispana, planteada en el último epígrafe, era tan pertinente: «[las mujeres] ¿no tienen alma racional como los hombres?».

\section{BIBLIOGRAFÍA}

ALATORRE, Antonio. 1986. «Sor Juana y los hombres». Estudios, 7, pp. 7-27.

ALATORRE, Antonio. 1987. «La Carta de Sor Juana al P. Núñez». Nueva Revista de Filologia Hispánica, 35.2, pp. 591-673.

ALATORRE Antonio y Martha Lilia TENORIO. 1998. Serafina y Sor Juana, México, El Colegio de México.

BERGMANN, Emilie L. 1993. «Ficciones de Sor Juana: poética y biografía» en Sara POOT-HERRERA (ed.), «Y diversa de mí misma / entre vuestras plumas ando», Homenaje Internacional a Sor Juana Inés de la Cruz, México, El Colegio de México, pp. 172-183.

BIJUESCA, Koldobika Josu. 1998. «'Una mujer introducida a teóloga y escriturista: exégesis y predicación en la Respuesta» en K. Josu BIJUESCA y Pablo A. J. BRESCIA (eds.), Sor Juana \& Vieira, trescientos años después, anejo de Tinta, Santa Barbara, University of California, Santa Barbara, pp. 95-112.

BRAVO, María Dolores. 1993. «La excepción y la regla: una monja según el discurso oficial y según Sor Juana» en Sara POOT-HERRERA (ed.), « $Y$

${ }^{35}$ Hay que recordar que sor Juana murió contagiada mientras cuidaba a sus hermanas enfermas de la peste que azotaba al convento de San Jerónimo.

36 Cfr. Sara Poot Herrera, «La caridad de Serafina, fineza de Sor Juana».

37 Haría falta explorar las referencias a la razón y el entendimiento en la CSC (passim). 
diversa de mí misma / entre vuestras plumas ando», Homenaje Internacional a Sor Juana Inés de la Cruz, México, El Colegio de México, pp. 35-41.

BRESCIA, Pablo A. J. 1997. «Sor Juana y el Padre Vieira: un baile de disfraces» en Nuevos territorios de la literatura latinoamericana. Buenos Aires, Instituto de Literatura Hispanoamericana; Facultad de Filosofía y Letras, pp. 47-54.

BRESCIA, Pablo A. J. 1998a. "Towards a New Interpretation of the Carta Atenagórica», en K. Josu BIJUESCA y Pablo A. J. BRESCIA (eds.), Sor Juana \& Vieira, trescientos años después, anejo de Tinta, Santa Barbara, University of California, Santa Barbara, pp. 45-52.

BRESCIA, Pablo A. J. 1998b. «El 'crimen' y el castigo: la Carta Atenagórica, de Sor Juana Inés de la Cruz», Caravelle: Cahiers du Monde Hispanique et Luso-Brésilien, 70, pp. 73-96.

CALLEJA, Diego. [1700] 1980. Vida de Sor Juana. «Aprobación de la Fama y obras póstumas», Madrid, 1700 en Sor Juana Inés de la Cruz ante la historia, Francisco DE LA MAZA (ed.), México, Universidad Nacional Autónoma de México, pp. 139-153.

CAMARENA CASTELLANOS, Ricardo. 1995. «'Ruido con el Santo Oficio': Sor Juana y la censura inquisitorial» en Margarita PEÑA (comp.), Cuadernos de Sor Juana, México, Universidad Nacional Autónoma de México, pp. 283-306.

CORRIPIO RIVERO, Manuel. 1967. «Sor Juana Inés de la Cruz: un punto en la Carta Atenagórica», Revista de Indias, 27, pp. 199-202.

CRUZ, Sor Juana Inés de la. [¿1682?] 1981. Carta de la Madre Juana Inés de la Cruz, escrita al R. P. M. Antonio Núñez de la Compañía de Jesús, en Autodefensa espiritual de Sor Juana, Aureliano TAPIA MÉNDEZ (ed.), pról., Raúl RANGEL FRÍAS, Monterrey, Universidad Autónoma de Nuevo León.

CRUZ, Sor Juana Inés de la. [1691] 1996. Carta de Serafina de Cristo. (1691), edición facsimilar, introd. y transcripción paleográfica de Elías TRABULSE, Toluca, México, Instituto Mexiquense de Cultura.

CRUZ, Sor Juana Inés de la. [1691] 1997. Carta q[ue] aviendo visto la Athenagórica q[ue] con tanto acierto dio a la estampa Sor Philotea de la Cruz del Convento de la Santíssima Trinidad de la ciudad de Los Ángeles escribía Seraphina de Christo en el Convento de N. P. S. Gerónimo de México, introd., y transcripción paleográfica de Elías TRABULSE, pról., Sara POOT-HERRERA, Los Ángeles, Aldan. 
CRUZ, Sor Juana Inés de la. [1695] 1994. Enigmas ofrecidos a la Casa del Placer, Antonio ALATORRE (ed.), México, El Colegio de México.

CHÁVEZ, Ezequiel. 1931. Ensayo de psicología de Sor Juana Inés de la Cruz y de estimación del sentido de su obra y de su vida para la historia de la cultura y de la formación de México, Barcelona, Araluce.

CHECA, Fernando. 1995. «Arquitectura efímera e imagen del poder» en Sor Juana y su mundo: una mirada actual, México, Universidad del Claustro de Sor Juana, Gobierno del Estado de Puebla y Fondo de Cultura Económica, pp. 253-305.

DORANTES, Augustín, fray. [1691] 1997. «Censura inquisitorial del sermón panegírico La fineza mayor» en Carta de Seraphina de Cristo, introd., y transcripción paleográfica de Elías TRABULSE, Los Ángeles, Aldán, pp. 59-65.

FRANCO, Jean. 1993. «Las finezas de Sor Juana» en Sara POOT-HERRERA (ed.), "Y diversa de mí misma / entre vuestras plumas ando». Homenaje Internacional a Sor Juana Inés de la Cruz, Homenaje Internacional a Sor Juana Inés de la Cruz, México, El Colegio de México, pp. 247-256.

GLANTZ, Margo. 1990. «Las finezas de Sor Juana: Loa para El Divino Narciso» en José AMEZCUA y Serafín GONZÁLEZ (eds.), Espectáculo, texto y fiesta. Juan Ruiz de Alarcón y el teatro de su tiempo, México, Universidad Autónoma Metropolitana, pp. 67-75.

GLANTZ, Margo. 1995. Sor Juana Inés de la Cruz: ¿hagiografía o autobiografía?, México, Grijalbo.

KIRK, Pamela. 1998. Sor Juana Inés de la Cruz: Religion, Art and Feminism, New York, Continuum.

LAVRIN, Asunción. 1995. «Vida conventual: rasgos históricos» en Sara POOTHERRERA (ed.), Sor Juana y su mundo: una mirada actual, México, Universidad del Claustro de Sor Juana, Gobierno del Estado Libre y Soberano de Puebla, Fondo de Cultura Económica y Grupo Carso, pp. 35-91.

LUDMER, Josefina. 1984. «Las tretas del débil» en La sartén por el mango, en (eds.), P. E. GONZÁLEZ y E. ORTEGA, Puerto Rico, Huracán, pp. 47-54.

LUISELLI, Alessandra. 1993. El Sueño manierista de Sor Juana Inés de la Cruz, México, Universidad Autónoma del Estado de México; Gobierno del Estado de México.

MARTÍNEZ LÓPEZ, Enrique. 1968. «Sor Juana Inés de la Cruz en Portugal: un desconocido homenaje y versos inéditos», Revista de Literatura, 33, pp. 5384. 
MARTÍNEZ LÓPEZ, Enrique. 1998. «Sor Juana, Vieira y Justo Lipsio en la Carta de Sor Filotea de la Cruz» en K. Josu BIJUESCA y Pablo A. J. BRESCIA (eds.), Sor Juana \& Vieira, trescientos años después, anejo de Tinta, Santa Barbara, University of California, Santa Barbara, pp. 85-93.

Memoria del Coloquio Internacional Sor Juana Inés de la Cruz y el pensamiento novohispano. 1995. México, Instituto Mexiquense de Cultura.

MÉNDEZ, María Águeda (coord.) 1997. Catálogo de textos marginados. Inquisición: siglo XVII, México, El Colegio de México, Archivo General d e la Nación y Fondo Nacional para la Cultura y las Artes.

MÉNDEZ PLANCARTE, Alfonso y Alberto G. SALCEDA, eds. 1951-57. Obras completas de Sor Juana Inés de la Cruz, 4 vols., México, Fondo de Cultura Económica.

MERRIM, Stephanie, ed. 1991. Feminist Perspectives on Sor Juana Inés de la Cruz, Detroit, Wayne State University Press.

MORAÑA, Mabel. 1998. «Sor Juana y sus otros. Núñez de Miranda o el amor del censor» en Margo GLANTZ (ed.), Sor Juana Inés de la Cruz y sus contemporáneos, México, Universidad Nacional Autónoma de México y Centro de Estudios de Historia de México Condumex, pp. 319-331.

OVIEDO, Juan Antonio de. 1702. Vida ejemplar, heroicas virtudes y apostólicos ministerios de el V. P. Antonio Núñez de Miranda de la Compañía de Jesús, México, Herederos de la viuda de Francisco Rodríguez Lupercio.

PASCUAL BUXÓ, José. 1993. El enamorado de Sor Juana, México, Universidad Nacional Autónoma de México.

PAZ, Octavio. [1983] 1997. Sor Juana Inés de la Cruz o Las trampas de la fe, 9a. reimp, Barcelona, Seix Barral.

PERELMUTER, Rosa. 1983. «La estructura retórica de la Respuesta a Sor Filotea», Hispanic Review, 51, pp. 147-158.

POOT HERRERA, Sara. 1997. «La caridad de Serafina, fineza de Sor Juana» en Martha Elena VENIER (ed.), Varia lingüistica y literaria. 50 años del CELL, vol. 2, Literatura: de la Edad Media al siglo XVIII, México, El Colegio de México, pp. 331-368.

POOT HERRERA, Sara. 1998a. «Una carta finamente calculada: la de Serafina de Cristo» K. Josu BIJUESCA y Pablo A. J. BRESCIA (eds.), Sor Juana \& Vieira, trescientos años después, anejo de Tinta, Santa Barbara, University of California, Santa Barbara, pp. 127-141. 
POOT HERRERA, Sara. 1998b. «Las cartas de Sor Juana: públicas y privadas» en Margo GLANTZ (ed.), Sor Juana Inés de la Cruz y sus contemporáneos, México, Universidad Nacional Autónoma de México y Centro de Estudios de Historia de México Condumex, pp. 291-317.

RICARD, Robert. «António Vieira y Sor Juana Inés de la Cruz», Revista de Indias, 12, pp. 61-87.

SABAT DE RIVERS, Georgina. 1998. En busca de Sor Juana, México, Universidad Nacional Autónoma de México.

SCHONS, Dorothy, 1926. «Some Obscure Points in the Life of Sor Juana Inés de la Cruz», Modern Philology, 24, pp. 141-162.

TAVARD, George H. 1991. Juana Inés de la Cruz and the Theology of Beauty. The First Mexican Theology, Notre Dame, University of Notre Dame Press.

TERRAZAS, Ana Cecilia. 1996. «La Carta de Serafina de Cristo no es autógrafa de Sor Juana, revela un peritaje». Proceso, 1052, 29 de diciembre, pp. 62-65.

TRABULSE, Elías, ed. y estudio introductorio. 1995a. Carta Atenagórica de Sor Juana, México, Condumex.

TRABULSE, Elías. 1995b. El enigma de Serafina de Cristo: acerca de un manuscrito inédito de Sor Juana Inés de la Cruz (1691), México, Instituto Mexiquense de Cultura.

TRABULSE, Elías. 1995c. «La guerra de las finezas» en Memoria del Coloquio Internacional Sor Juana Inés de la Cruz y el pensamiento novohispano, pp. 483-493.

TRABULSE, Elías. 1995d. Los años finales de Sor Juana: una interpretación (1688-1695), México, Condumex.

TRABULSE, Elías. 1996. La memoria transfigurada: tres imágenes históricas de Sor Juana, México, Universidad del Claustro de Sor Juana.

VOLEK, Emil. 1998. "La señora y la ilustre fregona: las trampas de comunicación, teología y poder entre Sor Filotea y Sor Juana» en Margo GLANTZ (ed.), Sor Juana Inés de la Cruz y sus contemporáneos, México, Universidad Nacional Autónoma de México y Centro de Estudios de Historia de México Condumex, pp. 333-357.

WISSMER, Jean-Michel. 1998. Las sombras de lo fingido: sacrificio y simulacro en Sor Juana Inés de la Cruz, México, Instituto Mexiquense de Cultura. 